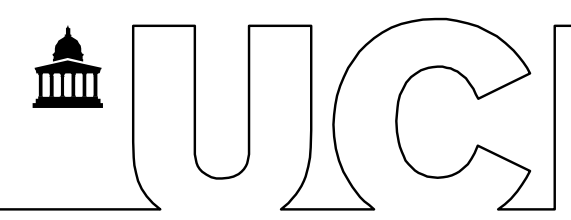

Castán Broto, V; Macucule, DA; Boyd, E; Ensor, J; Allen, C; (2015) Building collaborative partnerships for climate change action in Maputo, Mozambique. Environment and Planning A , 47 (3) pp. 571-587. 10.1068/a140070p. Downloaded from UCL Discovery: http://discovery.ucl.ac.uk/1456362

\title{
ARTICLE
}

\section{Building Collaborative Partnerships for Climate Change Action in Maputo, Mozambique}

\author{
Castán Broto, Vanesa'; Macucule, Domingos Augusto²; Boyd, Emily ; Ensor, Jonathan ${ }^{4}$; Allen, \\ Charlotte \\ ${ }^{1}$ School of BEAMS, University College London \\ ${ }^{2}$ Faculty of Architecture and Physical Planning, University Eduardo Mondlane, Maputo, \\ Mozambique. \\ ${ }^{3}$ Department of Geography and Environmental Science, Reading University \\ ${ }^{4}$ Stockholm Environment Institute, University of York \\ ${ }^{5}$ Independent consultant
}

\begin{abstract}
This paper examines partnerships as a policy strategy for climate change governance in cities in the global south. Partnerships offer the opportunity to link the actions of diverse actors operating at different scales, and thus, they may be flexible enough to deal with uncertain futures and changing development demands. Simultaneously, partnerships may lack effectiveness in delivering action at the local level, and may constitute a strategy for some actors to legitimate their objectives in spite of the interests of other partners. Engaging with the specific example of urban governance in Maputo, Mozambique, this paper presents analysis of potential partnerships in this context, in relation to the actors that are willing and able to intervene to deliver climate change action. We ask, what are the challenges to achieving common objectives in partnerships from the perspective of local residents in informal settlements? Our analysis describes a changing context of climate change governance in the city, in which the prospects of access to international finance for climate change adaptation are moving institutional actors towards engaging with participatory processes at the local level. However, our analysis poses a question about the extent to which local communities are actually perceived as actors with legitimate interests who can intervene in partnerships and whether their interests are recognised.
\end{abstract}

\section{Introduction}

"Governance based on partnerships has become a characteristic of late capitalist societies" (Sherlock et al., 2004; p. 651)

Debates about adapting cities to climate change highlight the need to develop strategies that address urban vulnerability to climate change. Both the uneven distribution of vulnerabilities to climate change and its differential impacts suggest that any programme to tackle climate change adaptation will raise equity and justice questions (Adger, 2006; Paavola and Adger, 2006). Many of these dimensions come to the fore when thinking about adapting to climate change within urban areas, particularly in relation to the need to develop locally-driven strategies that involve those who are most at risk (Satterthwaite, 2007). In African cities, adaptation actions need to be coupled with pro-poor forms of urban development. However, the experience of planning in African cities demonstrates that planning has most often worked towards exacerbating poverty (Watson, 2009). In this paper, we argue for an engagement with practical forms of knowledge that emerge from everyday experiences of living in the city. 
From January 2011 until July 2013 our team, with the support of the National Environmental Fund (FUNAB), implemented a project of participatory planning for climate change in the neighbourhood of Chamanculo C, in Maputo, Mozambique. After several months of community negotiations, residents elected five citizens as members of a Climate Planning Committee (CPC) which developed a 'Community Plan for Climate Change Adaptation'. Residents of Chamanculo C proposed measures to improve the neighbourhood's waste management and drainage through community organisation, repairing networks to improve the water supply, and improve waste management with a new recycling centre. However, they rejected the option of relocation because they believed it would have an unbearable impact on their livelihoods. While the project's facilitators created a forum for discussions, the CPC led the development of proposals, wrote a community development plan, and defended it in front of representatives of national and municipal government. They found that a lack of institutional support hindered the implementation of their proposals.

The CPC concerns led our team to evaluate possible avenues through which citizens could intervene in climate change governance. If governance refers to the multiple aspects through which diverse actors intervene in controlling and managing the city, partnerships emerge as the ongoing process through which such actors- government, business, civil society, people- are engaged in governance. This notion resonates with the idea of cross-sector partnerships, which extends the more ubiquitous but narrow notion of public-private partnership as a specific type of contract in service delivery (Selsky and Parker, 2005). Understood in this way, partnerships offer the opportunity to link the actions of diverse actors operating at different scales, and may be flexible enough to deal with uncertain futures and changing development demands (Okereke et al., 2009; Schroeder et al., 2013; Leck and Simon, 2013). As a form of institutional development, partnerships represent new sets of norms and conventions, explicitly stated or not, that help to coordinate actions across different interests and scales (Boyd and Folke, 2011). There is empirical evidence of multi-level partnerships for climate change governance in cities around the world (Castán Broto and Bulkeley, 2013). Initiatives building partnerships for climate change in cities such as Cape Town and Durban demonstrate that they help to build linkages across different types of knowledge (Cartwright, Parnell et al, 2012; Leck, 2013). However, partnerships are also open to appropriation by some actors and may not always be the most effective mechanism for delivering urban services (UN-Habitat, 2009). In the context of Maputo, the question is the extent to which partnerships can deliver forms of pro-poor planning that address climate change risks in cities in Africa.

To do so, partnerships will need to engage with local knowledge through a process of shared learning (ISET, 2010), similar to the one we conducted in Maputo. Through this process, partnerships should empower citizens living in impoverished and subserviced settlements to find collectively practical ways to improve their lives and reduce their vulnerability to climate change risk. This paper reports on the experience of trying to build such a partnership in Maputo- including public and private actors, but also explicitly 'people', that is, urban citizens. This was a process of participatory planning which fostered constructive dialogues among government representatives, businesses and communities seeking to deploy forms of collaborative rationality, that is, agreement achieved through negotiation and dialogue (Forester, 1999; Healey, 1997; Innes and Booher, 2010). The paper focuses on understanding the conditions that enable a step-change from mere dialogue to the establishment of truly operative cross-sector partnerships between public, private and civil society actors (cf. Healey, 1997). In relation to the context of urban governance in Maputo, the paper establishes, first, the extent to which there is a critical mass of institutional actors to engage with local communities in delivering actions to adapt to climate change and, second, whether any of these actors are open to work with communities in reappraising their own objectives. In doing so, this paper examines critically the idea of cross-sector partnerships for climate change as emerging within the paradigm of cooperative environmental governance and its potential to develop alternatives for pro-poor, climate-conscious urban planning.

\section{Partnerships as a form of cooperative environmental governance}

The notion of partnership is still most often deployed in relation to the public-private partnership model, as a mechanism whereby the private sector can come to the rescue of the public sector 
that is portrayed as lacking the capacity to deliver public services. There is ample evidence, in sectors from waste management to transport planning, of how public-private partnerships advance neoliberal logics making the investment landscape attractive to private business, without delivering a parallel benefit for the public good (Ferreira da Cruz et al., 2013; Siemiatycki, 2011). There is also evidence of how partnerships support unsustainable growth models and land appropriation which affect directly the most vulnerable leading, for example, to the legitimisation of neoextractivist policies in the Amazon (Baletti, 2014) or to projects with direct negative impact on the lives of the urban poor in Indian cities (Sengupta, 2013). Partnerships, thus, have been approached with caution both in terms of their potential appropriation and the extent to which disadvantaged groups can actually participate meaningfully in the process of constitution and implementation of the partnership (O'Malley, 2004).

An alternative approach, cross-sector partnerships, refers to the diverse and flexible association models that emerge to facilitate the urban governance of climate change (Castán Broto and Bulkeley, 2013). This is close to the notion of partnerships within cooperative environmental governance perspectives (Glasbergen et al., 2007), which emphasise management regimes as forms of "social regulation in which groups originating in different spheres of social life, and reflecting distinct perspectives and interests, participate in debate and negotiation to achieve a common understanding of a scientific problem, and then implement a collective plan for its resolution" (Meadowcroft, 1999; p. 22). In this vein, partnerships bring together a cross-section of actors with different interests but implicated in what they regard as a common problem (Glasbergen, 1998). Like public-private partnerships, ideas behind cooperative environmental governance relate to an overall withdrawal of traditional forms of government. However, in the context of cities in developing countries, cooperative environmental governance may actually reflect the actual state of affairs in which the lack of capacity of the government forces or enables a multiplicity of actors- from citizens to businesses and civil society organisations- to intervene in public urban life.

Brinkerhoff defines partnership "as a dynamic relationship among diverse actors, based on mutually agreed objectives, pursued through a shared understanding of the most rational division of labour based on the comparative advantages of each partner" (Brinkerhoff, 2002; p. 216). A collaborative partnership entails not just agreeing to deliver common action in relation to each partner's capacities, but rather the fulfilment of an agreed common goal, the sharing of both responsibilities and risks and the transfer of skills and know-how between partners. To achieve this, Brinkerhoff argues, partnerships need to achieve high levels of mutuality (in terms of recognizing and responding to the interests of each partners) and high levels of organizational identity (in terms of maintaining the original purpose for the partners involved).

A central question is the extent to which communities can be directly involved in collaborative partnerships and if so, what should be the nature and manner of their involvement (Plummer and Fitzgibbon, 2004a, b). Communities may struggle to be recognised as equal members in a partnership and hence, alternative modes of cooperative environmental governance are required. Communities may lack an organisational identity that distinguishes their interests. The need to recognise the heterogeneity of communities, especially the way power relations play out in practice, has long been a driver of reform within debates on the potential misgivings about participation (Cooke, 2002; Evans and Varma, 2009). Potential partners may not recognise communities as a differentiated interest group, and hence, they may struggle to enter a partnership in equal conditions. Moreover, the ephemeral nature of most partnerships, subject to the availability of resources may further result in cynicism about their purposes and hinder their operation (Holman, 2013).

Forsyth $(2005,2007)$ has reassessed the nature of partnerships as resulting from an ongoing deliberative process. Building on the hypothesis of institutional diversity, Forsyth redefines partnerships "as sites where norms of environmental concern and political accountability are formulated and replicated" (Forsyth, 2005; p. 429). In this context, deliberative public-private partnerships are directed towards maximizing opportunities for public debate among a wide range of actors within the spheres of government, market and civil society, with an explicit focus on 
inclusiveness and establishing the relevance of partnership goals to local needs. In emphasizing the notion of partnership as a deliberative process, rather than as an established mechanism for the achievement of prefigured goals, Forsyth directs attention to both process and outcomes, highlighting that new norms and legitimisation processes may follow the development of a partnership. Mutuality and organisational identity remain crucial but they are not fixed at any given moment; rather they can be accomplished by the actors intervening in partnership as they adopt new roles and intervene in constant negotiation. In a governance process shaped by powercentred interactions (Meadowcroft, 1999), partnerships open up negotiation arenas to unheard voices who can challenge dominant governance arrangements. Understood in this manner, crosssector partnerships relate closely to the efforts to achieve tangible outcomes from participatory planning processes. Finding appropriate ways to articulate multiple points of view, especially those of the voiceless, remains the key concern in the constitution of collaborative partnerships for environmental management (Sherlock et al., 2004).

How do we build partnerships that recognise citizens' objectives and bring communities as equal partners into the delivery of such objectives? This requires both identifying potential partners and developing methods to establish networks of actors to support such partnership. From a cooperative environmental governance perspective we focus in two aspects of that question: first, who are the organisations with both organisational identity and high levels of mutuality, which share a common stake in planning for climate change? Second, to what extent do these organisations recognise the role of communities within a partnership (see: Healey, 1997; Holman, 2013)? The experience of building a "public-private-people- partnership" (4P) in Maputo, with a double strategy to build communities' capacity to intervene in partnerships and gaining purchase within urban governance processes, provides an insight into the potential of cross-sector partnerships to address climate change and the limitations that the urban context of Maputo poses for cooperative environmental governance.

\section{Background and methods}

Maputo is the capital and the most populated area in Mozambique, with 1.1 million inhabitants. Located in the Maputo Bay, Maputo is exposed to the influence of the Indian Ocean. According to the National Institute for Disaster Risk Reduction (INGC, 2011), climate change will increase the risk of flooding, cyclones and sea level rise in Maputo. The multi-dimensional poverty index indicates that $44 \%$ of the population in Maputo is in poverty (Alkire et al., 2011). There is a stark contrast between the 'cement city' and the impoverished informal city that is organised in suburban wards or 'bairros'.

Chamanculo $\mathrm{C}$ is an example of such a 'bairro'. It is an historical neighbourhood where entrepreneurs within mostly informal economies and salaried workers live. Each neighbourhood is divided in smaller quarters and groups of 10 houses which may organise themselves collectivelyin 'communities'- to address immediate issues within their neighbourhood. Access to services and infrastructure is one of the main aspects of urban deprivation in Maputo. For example, $33 \%$ of the population in Maputo depends on a pit latrine (Andersen et al, 2012). In Chamanculo $C$ the main aspects of deprivation relate to the unsurfaced, undulating streets, lack of or deficient drainage and sanitation, unreliable water supply and irregular access to emergency services. Addressing climate change in Maputo will require bold adaptation measures addressing the lack of services, the need for improving drainage and storm water systems and the protection of households and green areas (MMC et al., 2012; UN-Habitat, 2009).

A recent study by UN-Habitat mapped out the key actors and regulations that could have an influence on climate change action in Maputo (Castán Broto et al., 2013), including the Ministry of Environment (MICOA) and the National Institute for Disaster Risks Reduction (INGC). They emphasised the role of the Maputo Municipality and the diverse efforts displayed in developing strategies and plans that could address climate change. The report, however, also showed: 1) that there is little effective action for adapting to climate change on the ground; and 2) that Maputo's citizens are seldom considered as active actors who can intervene for climate change adaptation in their city. From the concerns of the national government, as expressed by representatives of FUNAB a project emerged to constitute partnerships for climate change that would fully recognise 
citizens as active partners and would find the mechanisms to integrate them directly into policy making and implementation. Following the insights from the literature on partnerships, we mapped the potential for new institutional arrangements for climate change governance within the existing urban governance landscape of Maputo. Our study looked into: 1) who, in Maputo, would join the communities in a partnership to deliver climate change action; and 2) the extent to which other actors would be open to work alongside and in response to the concerns of local actors.

The methodology was thus designed to answer these research questions. The first question was directed at identifying the main actors who could be involved in action for climate change in Maputo. We approached this question as a stakeholder analysis through reconstructive characterisation, that is, defining stakeholders in relation to self-reported information (Reed et al., 2009). We developed a preliminary list of 73 actors following document analysis and consultation with key informants in UN-Habitat, FUNAB and Eduardo Mondlane University in Maputo. The list included actors who our informants regarded as having the capacity to intervene, even when they had not declared explicitly a concern with climate change.

This included actors from public organisations and government; international organisations; educational institutions; private and business sector; NGOs (both international and local); loosely configured civil society networks and associations. We analysed each actor's statements of mission and, when available, the documentary evidence of climate change action. In a few cases we relied on information from our informants, particularly with regards to the significance of any such organisation to deliver climate change action. For each actor we coded their interest in climate change, development, disaster risk reduction, urban planning and their declared scale of operation. We also assessed what aspect of climate compatible development was prioritised in the organisation's objectives and values (Development, Mitigation, or Adaptation). Finally, we recorded their main strategies of operation in Mozambique, to understand their specific role in climate change governance. The analysis originally followed Bulkeley and Kern's (2007) analysis of modes of climate change governance (regulation, provision, enabling and self-regulation). However, as the analysis advanced we felt necessary to redefine the categories as follows: 'Project delivery' relates to a focus on concrete projects to be implemented on the ground. 'Institutional development' refers to activities that are directed towards facilitating communication and integration across organization, or delivering new forms of regulation. Organisations involved in 'finance and resources' focus on mobilising different resources to facilitate the activities of other organisations. Finally, 'lobbying and activism' highlights a focus on collective mobilization and social action through campaigning.

The second question is whether these actors could deliver climate change action alongside and responding to the concerns of citizens and communities. This refers to how stakeholders situate themselves in relation to other actors, especially communities, within the current landscape of urban governance. Discourse analysis is an analytical tool to study social relations through language. Social psychologists have described speech as performative: as an act with intentions and consequences (Potter and Wetherell, 1987). A critical analysis of such speech acts within broader processes of institutional and social change illuminates the imbrication between discourse, power and the imagined spaces of possibility (Wetherell, 1998). In the case of climate change action in Maputo, speech acts relate to both the attribution of responsibility and the recognition of capacities to act in response to climate change threats. Our analysis described 'doxas' (Bourdieu, 1998)- recognisable accounts of certain positions- to draw the contours of dominant accounts about what kind of environmental action is desirable and how will be achieved (Castán Broto, 2013 following Bourdieu, 1998).

This analysis focused on a sub-section of organizations that were initially identified as relevant for local communities. We conducted 21 semi-structured interviews with representatives of such organisations, including ministries and agencies in the national government (7), municipality departments (3), international organizations (4) and organizations from civil society (7). This last category includes organisations representing the local community and organisations that, although they present themselves as NGOs or associations, may also represent local business interests, such as the Mozambican Association for Recycling (AMOR) which focuses on the 
commercialisation of recycled waste. Each interview followed an interview guide that explored urban governance, climate change and the potential for participation in Maputo. For confidentiality reasons we could only tape 7 interviews, and thus, the analysis relies largely on notes taken during the interviews.

\section{Organisations and climate change action in Maputo}

Our actor-mapping exercise included 73 organisations and interest groups who intervene at different scales from the local to the international level (Table 1). The majority of actors mapped were NGOs (34), although there is a clear presence of international development institutions and government, private sector, and to a lesser extent, networks and educational institutions. The group of NGOs, however, is very heterogeneous as it includes actors who differ greatly in terms of their objectives and their style and scale of operation, including for example, NGOs that operate at the international level (e.g. CARE international, Save the Children, Caritas) and those that intervene at national or local scales.

\section{Table 1: Actor-mapping analysis}

Most of the organisations surveyed had a broad remit of operation, with only six describing themselves as operating within the city and two at a neighbourhood level. Some actors operating at larger scales also intervene at the local level, and for the majority, Maputo is their centre of operation, which naturally leads to many projects being based in Maputo. Some actors, in particular international NGOs, mobilise resources and deliver projects at different scales.

Only 29 of 73 organisations (40\%) made explicit mention of climate change as one of their main interests although a greater number $(34 ; 47 \%)$ were concerned with Disaster Risk Reduction. Most actors were concerned with development and poverty reduction (54 actors, $74 \%$ of the sample). From the whole sample, 30 organisations (41\%) considered urban planning as a strategy for intervention. Only 10 actors (14\%) considered all four (climate change, disaster risk reduction, development and poverty reduction and urban planning). These included bilateral cooperation institutions; international organisations such as UN-Habitat, the World Bank and the Cities Alliance; the Maputo Municipal Council and the local organisation Livianingo. Most of the NGOs focused on discrete issues. NGOs, networks, private sector and educational institutions tended to consider urban development less often than not, as opposed to international organisations and government institutions.

We also analysed which dimensions of climate compatible development- mitigation, adaptation, development- were prioritised in the objectives of different organisations poised to intervene in the urban environment. Table 1 provides an overview of the number of actors that prioritised each objective. Development was the main priority for most institutions. Fewer prioritise adaptation and even fewer mitigation. Adaptation is a concern especially among governmental and educational institutions, and to a lesser extent among networks and NGOs. Mitigation features prominently among interventions of NGOs, government, international development organisations and the private sector. Given the urgent nature of adaptation challenges in Maputo and the vulnerabilities that have been made particularly visible during floods in the last two decades, the prominence of mitigation concerns among NGOs and the private sector was unexpected. However, many interventions directed at mitigation can also be framed as development interventions in the sense that they attempt to extend the provision of energy or other services to urban dwellers in a sustainable manner. Urban planning tends to be considered more often by organisations whose main climate compatible development priority is mitigation, reflecting that concerns with adaptation are most often displayed at larger geographical scales.

Table 1 also shows the main strategies that actors employ to intervene in the urban environment. Most of them (53\%) focused on project delivery and project implementation. Institutional development is, however, an activity found across a diverse set of organisations, from networks to NGOs, to public institutions. Financing organisations and donors included microcredit organisations (e.g. the Community Credit Fund), government (e.g. FUNAB), philanthropic organisations (e.g. Lourdes Matola Foundation) or international organisations (e.g. UNIDO). 
Activism was a rare action mode, advocated only by the local environmental organisation Justiça Ambiental and the International NGO that supports informal settlement dwellers networks- Slum Dwellers International. Lobbying was limited to business-oriented organisations (such as the Business Forum for the Environment and the Confederation of Business Associations).

The analysis shows that, in the context of Maputo, there is a strong focus on project delivery for development and poverty alleviation. Climate change emerges as a secondary concern, most often brought upon by actors operating in international arenas. This poses a question of strategy in terms of forming partnerships that deliver added value by engaging with both climate change and local development priorities, and in a manner that prioritises the urgent needs for adaptation in Maputo.

\section{Perceptions of urban governance and climate change}

This section analyses each actor's accounts of urban governance and climate change in Maputo, their perceived capacity for intervention and the extent to which they emphasised community participation, as expressed by representatives of each organization. All interviewees were concerned with climate change. However, the way discourses of risks and uncertainty were constructed was diametrically different, particularly in terms of the attribution of responsibilities to different actors and their possibilities to take action. For example, Table 2 summarises five different accounts on one of the main climate change risks, flooding, and how these relate to prescriptions to act upon it.

\section{Table 2: Five different accounts of flooding in Maputo}

The key characteristic that distinguishes such perspectives is the scale at which the event is regarded and at which interventions are sought. At a global level, flooding is linked to climate change, and the overall responsibility falls upon humanity as a whole (account 1). This was the dominant account across international organisations, as well as with some key government institutions. In some cases, these interviewees also took a regional perspective to emphasise flooding as a natural catastrophe, one that required Disaster Risk Reduction measures enrolling the whole population, such as the account of the INGC (account 2). At the city level, however, flooding accounts locate responsibilities closer to home. Several representatives of municipal departments, for example, related flooding with the planning and location of the city (account 3); for others, flooding, however, was related to the way settlements spread, and attributed responsibilities directly to the urban poor for bringing upon them risk by constructing their homes in risk-prone areas (account 5). The emphasis on service provision delivery, and the responsibility of local authorities for providing adequate services to reduce vulnerability to flooding, however, was only emphasised in the accounts of locally-based civil society organisations. All accounts recognised, however, the complex interaction of climate change risks with other urban health problems. The representative of the municipality, for example, highlighted climate change together with other urban problems including air pollution, flooding, waste, but specially water provision because "who speaks of water, speaks of drinking contaminated water, and then with the rainwater come the mosquito and moreover, there are related problems of sanitation" (Interview 1, municipality $\left.{ }^{1}\right)$.

Flooding is constructed as an issue in relation to the provision of urban infrastructure, the key aspect for intervention from a local community perspective. For actors focusing on the international or regional levels, communities have importance but only because they have to be controlled (see Boyd et al, 2014). Those who focus on interventions at the local level (accounts 3,4,5) recognise the importance of settlement patterns and vulnerability factors to understand how climate change risks play out in the city. A government official explained: "Maputo is flood prone, with or without climate change. The city was founded in a geological depression. The 1963 or 69 Master Plans

\footnotetext{
${ }^{1}$ Interviews have been numbered and names withdraw to protect the anonymity of interviewees. Each quote includes a reference to the institutional type i.e. municipality, (other) government, NGO, international organisation. All interviews were conducted in Maputo, between March 2012 and August 2013.
} 
identified flood prone areas, but people built on them (informally) anyway. [There is] now inadequate drainage, and water accumulates" (Interview 15, government). The assumption is that the 69 Master Plan could have dealt with the drainage and water accumulation problems of a city already built in a geological depression, as if flooding risks could be easily managed with simple planning tools. However, putting poorer citizens at the other side of the acting equation- as those who cause the problem, rather than solving it- implies limiting the possibilities of concerted action against flooding.

These arguments contrast with the overall recognition, even among those who blame informal settlement dwellers for increasing the city's risk to flooding, that "the poorest population groups are most affected" (Interview 2, government). Public strategies, such as those from the municipality, are directed towards addressing these risks through the spatial relocation of citizens, and as municipal representatives explain "'Requalifying' of vulnerable areas goes on, as pre-emptive actions. The Councillor [representing local government] makes urban planning decisions, relocating people who then return. People continue to build on land that is susceptible to flooding" (Interview 5, municipality). In addressing erosion and flooding, the focus is on the reconstruction of sea walls, improving drainage in the cement city and extending the cement city through the extension of Julius Nyerere Avenue, which may entail the relocation of residents in the informal settlement of Polana Caniço. Risk reduction measures are thus concentrated in the old- and significantly more affluent- 'cement city', while the priority for intervention in informal settlements affected by flooding is relocation. Overall, this constitutes a differentiation of modes of urban governance alongside arguments of spatial differentiation that take uncritically the cement city as the only significant place for intervention.

This opposes the position of civil society organisations (account 4) who argue that the poor conditions of waste, sanitation and drainage infrastructures "constitute an attack on the welfare of the people because population health is compromised" (Interview 3, NGO). Municipal representatives argue that despite the sorry state of the subserviced suburbs "townspeople are also affected because drainage systems do not exist" (Interview 1, municipality), which refers again to the prioritisation of infrastructure upgrades in the cement city and expresses the underlying assumption that interventions in the old city need to be prioritised over addressing urban infrastructure shortages elsewhere in the city. This argument reveals an ongoing conflict between the institutional perceptions of city's needs and those of citizens. In Maputo, "flooding is seen as part of life; the Municipality's solution is relocation, while the community chooses to stay and live with it" (Interview 11, NGO). Moreover, relocated communities may find themselves being disadvantaged if new settlements also lack services and are further separated from social networks and livelihood sources.

This discussion is closely related to the second theme in the interviews, with regards to who has capacity to act and to address vulnerabilities to climate change risks. Many actors, especially international organisations and NGOs, identified the municipality as the key actor that should either deliver or mediate climate change action. Yet, those very actors acknowledged limitations in enrolling the municipal government in climate change action. Some highlighted that "local government ownership is lacking" (Interview 6, international organisation) or a "lack of dedicated personnel within the municipality" and that their approach is merely "reactive" (Interview 8, international organisation). For an NGO, commenting on the capacity of the municipality to intervene in disaster management "the municipality is apprehensive to hear complaints because they are fearful to hear about how bad is the job they are doing" (Interview 11, NGO). Moreover, administrative and regulatory efforts have not been translated into a clear programme for action, and indeed "we know that there are plans but we do not see anyone implementing those plans" (Interview 20, NGO). Yet, efforts to deal with climate change issues need to be appreciated, as far as they are mediated by dominant understandings of climate change risks which divert attention from public service provision needs, as explained above. Maputo municipality's partnership with the INGC, for example, has been highlighted as a strategy that builds resilience (Castán Broto et al, 2013; WB 2009). The INGC has a dedicated member based at the municipality's offices and they have together engaged with UN-Habitat and other organisations to work for disaster risk reduction. Some NGOs are appreciative of these efforts and explain that "INGC is doing a good 
job, reducing impacts... and working on scenarios: regulations exist but they are not applied." (Interview 10, NGO).

This gap between rhetoric and policy- between stated intentions and action on the ground- is not specific to Maputo. Scholarly research has demonstrated how ubiquitous such a gap is; arguing that moving beyond good intentions into transformative practices is one of the major challenges of climate change policy (Betsill and Bulkeley, 2007).This is visible in all public institutions in Maputo. Representatives at the ministerial level, for example, see themselves as "coordinating efforts and actors" (Interviews 2 and 4, government). Municipality representatives see themselves as providing a planning framework for private intervention, as they argue "the public is responsible for defining the rules but interventions correspond to the private individual" (Interview 1, municipality). For several interviewees the challenge is thus to incorporate climate change into municipal planning (Interview 5, municipality) or updating the climate change strategy (Interview 6, international organisation). The national authorities emphasised the need for a Master Plan for Maputo (Interview 15, government) or, at the very least, a slum upgrading strategy (Interview 8, international organisation). In all these arguments, the public realm of intervention is constructed as a place of strategy, knowledge and rule development with less emphasis on project implementation and delivery- in contrast with the broader analysis of discourses of climate change intervention emerging from our initial actor mapping (section 3.2).

Some actors, especially those in government and international institutions, see the landscape of urban governance changing with the arrival of climate finance. A representative of the government, for example, expected that due to climate finance, they were now looking at the "potential for receiving and managing up to $\$ 100$ million a year in climate resilience funding from multi-lateral agencies such as UNDP" (Interview 13, government). Some of the funding for adaptation measures has already been deployed with a focus "on process and multi-ministry grants" (Interview 6, international organisation). With these prospects, some public institutions (especially MICOA and INGC) are aware that strategy development without effective action is not enough. The Sustainable Technical Council (CONDES) is a key player that will arbitrate the allocation of international funds for climate change such as those coming from UNDP. CONDES has representation from various ministries and draws technical support from a technical council which includes representatives from the civil society, but has no mechanism for representing communities or citizens directly.

In this context, different actors are positioning themselves in relation to the potential to manage large funds for climate change action. Although this will not be exclusive to the urban setting, Maputo constitutes the arena of political alliances that can make practical projects possible, aside from its potential as a test bed for urban resilience projects. In this process INGC and MICOA are competing for recognition as the leading player in delivering climate change action on the ground. Indeed MICOA has "tensions with INGC about who is the key actor" (Interview 6, international organisation). Both institutions are attempting different strategies to build and demonstrate their capacity to act upon climate change. INGC, for example, emphasises its role in disaster risk reduction and its partnership with municipal governments- such as Maputo Municipality- as a way to deliver action at the local level. At the moment, "INGC is supporting the creation of four community disaster reduction teams through Maputo" and, although "it will need hundreds to have an impact" (Interview 16, international organisation), this shows an orientation towards working with communities. MICOA, on the other hand, has engaged directly with NGOs through the allocation of funds through FUNAB. Now both MICOA and FUNAB are interested in engaging with citizens and communities directly. They expect that their experience in participatory planning will help them influence decisions in CONDES (Interview 13, government). Equally other ministry representatives argue that they are "seeking to build ownership [of their projects] by involving the population from the beginning" (Interview 4, government).

There is interest in working with and engaging communities in climate change action. The key question here is whether this is regarded as an exercise of engagement, rather than co-optation of communities to support institutional objectives and the extent to which actions to engage with communities will go beyond paying lip service to the rhetoric used to deploy climate funds. Will 
communities be able to intervene meaningfully in partnerships? Without exception, all the actors mentioned that communities have a role to play in adapting to climate change. Yet, their views differed considerably in terms of the extent to which communities were perceived as being legitimate partners in urban governance, whether they should act with or without the tutelage of other actors, and the extent to which government and civil society organisations had the means to actually listen to them.

Institutional representatives have limited understanding of who 'the communities' are and how they can be represented. A government official explained that "community consultations are required by law, but there are problems about the representativeness of consultations" (Interview 15, government). This view was common across national government, municipality, international organisations and NGOs. For example, an NGO representative explained that while public participation was "very important, because you have to know what the person who lives the problems think", existing "mechanisms for people to be heard... in newspapers or television... exclude a large majority of the population" (Interview 3, NGO). Municipal representatives, for example, recognise that "plans are made for people, so they cannot be done in the offices, they have to be done with people and for people and especially, regarding the implementation of the plans, the private sector has to be called to participate" (Interview 1, municipality). However, the same representative argued that "the community should get together and make a claim that can get echo"... and that "people must organize themselves into associations to participate actively... [because] it takes the population to find mechanisms to be represented" (Interview 1, municipality). Overall, there is a preoccupation with who does each community represent and how citizens can engage effectively in ongoing processes of urban governance.

These questions also depend on the organisation of the civil society in traditional structures, structures emerging from the political organisation under FRELIMO (Mozambique Liberation Front) and new civil society organisations emerging within or alongside international NGOs and other external attempts to intervene in urban governance. For one member of the government a key aspect of organising the local community was to engage with the traditional authorities (O Regulo), that are present in every ward and whose authority is located in specific families and passed down through generations. While previously these traditional authorities were regarded as a backward legacy of the colonial era, now the government recognises their importance in shaping the space of action at the local level (Interview 15, government). Simultaneously, the governance structures inherited from the FRELIMO system, with a Bairro Secretary, a Chefe de Quarteirao and a Chefe das dez casas, are ubiquitous. Engaging with the community requires both their permission and their mediation. For some actors active in Maputo, the way community based organisations are established, through such politically-based structures, means that "they are not representative of the needs of citizens" and that "NGOs already in communities... will have a political position" (Interview 8, international organisation). The major difficulty is that chiefs and chefes control the process of citizen representation because, in practice, "the chief of the area will invite people to the meetings that we call - so we don't know whose views are being represented within the group" (Interview 8, international organization). For NGOs, the issue is that this governance structure hampers any attempt at forming politically active, interest-based organisations and that "few organisations are willing to take an advocacy role" (Interview 11, NGO); there is a general consensus that the FRELIMO structures "inhibit communities to take advocacy positions" (Interview 16, international organisation).

Overall the perception is that there are limited examples of communities actually effecting progressive change towards poverty and vulnerability reduction. And yet, there is clear evidence that in suburban and subserviced bairros such as Chamanculo, "people self-organize during floods cleaning drains, piling sand bags..." even though "government institutions do not know how to support and scale this up" (Interview 8, international organisation). However, there is also apprehension among community residents, particularly because of a perception that "each one does what they can and want without any coordination, for example, if I decide to extend my backyard because I got some money... I call the mason ... and say oh mason we have to conquer here a little over a meter. [This] reduces the size of the street; the buildings and plots will get tighter and disorderly, and the pathways you see will become less accessible" (Interview 21, NGO). 
For a few interviewees (both within the national government and NGOs) media- newspapers, radio, TV - constitute the means through which to communicate with the general public. The municipality highlights that direct mechanisms may not be appropriate because "in meetings and public hearings... people go to the meetings to present their concrete problems like drainage, but they are not too concerned with strategic issues", which poses a challenge because the municipality needs to learn then "how to accommodate these concrete requests in strategic plans" (Interview 1 , municipality). While the municipality has been effective in establishing partnerships with local groups, particularly in the area of waste management (Interview 5, municipality; Interview 10, NGO), the channels of communication are not effective, and indeed, there is fear that the information transmitted to the municipality via bairro institutions is often incorrect. The challenge is "how to open up a communication channel between citizens and municipality so that the former can express their views and the latter can understand their views" (Interview 11, NGO) without forcing the Municipality to admit their responsibility with regards to the overall lack of service provision in the bairros where most citizens live.

\section{What is the potential of collaborative partnerships for climate change in Maputo?}

The broad analysis of actors and actor-objectives does not correspond to the expressed positions of representatives of a selection of those actors in the qualitative interviews. While the document review showed an overall concern with development and poverty prioritised over climate change, and a focus on project delivery as an action strategy, qualitative interviews suggest that, especially for the public sector and international organisations, the focus is on strategy development and regulation. This may have to do with the sample, as the large sample analysed in the actor mapping have a majority of NGOs while the qualitative sample had a more balanced distribution of institutional organizations. Notwithstanding, this paints a wide gap between projected images and the actual operation of actions on the ground and the extent to which positions expressed officially in public documents match more complex understandings and strategies that emerge 'backstage' (cf. Porter and Demeritt, 2012). Such backstage accounts may not be explicit but they may influence directly the way action is developed and implemented.

The analyses also show how the urban realm is constructed as an area for concrete projects or rather, for strategy and planning. Both analyses speak to the need to consider climate change together with other development priorities. Poverty-reduction strategies and infrastructure provision are essential to ensure both an adequate supply of services and an increase in adaptive capacity by those who live there. The extent to which relocation should be prioritised over other forms of service delivery intervention (drainage, storm protection, preparedness, transport and communications) can only be determined when the potential for alternative strategies has also been evaluated. Looking at relocation as 'the easier option' disregards both the hardships that relocation may cause to those who face it in their lives and the institutional difficulties of actually delivering it- as in many cases relocations (and their associate violence) take place and then residents occupy the space again (also explained in Interview 21, NGO).

If the poor are the most affected; if the strategies that will deliver sustainable development and climate change resilience are to be based in communities and embraced by citizens; if communities have a social capital that can be mobilised for climate change: are there institutional mechanism to mobilise this potential? We have advocated partnerships between government institutions, private organisations, civil society and citizens as a means to deliver adaptive capacity and sustainable development. The question, here is to what extent the institutional context of Maputo provides the conditions for such partnerships to emerge.

There are actors who can intervene in the city for climate change. There are actors that are willing to hear local communities and their views. However, most actors found it difficult to conceptualise communities in a way that moved beyond consulting them to recognising them instead as comprising capable citizens who can share responsibilities and exchange skills with other partners. Moreover, most institutions bar a few NGOs saw themselves as necessarily having different objectives than those of local residents. The most surprising case in point is the municipality representatives who while acknowledging the municipality's responsibility for service delivery and the fact that citizens involved actively in consultations claimed this as a priority, still established a 
difference between their perspective- focus on strategy and rule-setting- and that of local residents who demanded services. For external observers in NGOs and international organisations this is a reflection of the limited progress that the municipality has done and its own struggle to gain legitimacy in the broader city.

Finding an identity and collective objective for communities is not an easy task in Maputo. While communities are organised through three types of civil society organisations (traditional, political and international base) these forms of organisation are thought to obscure rather than clarify community identities and, in the best of cases, represent only a partial view of what communities need and how they want it delivered. Yet, our experience with communities resonates with that expressed by several interviewees that on the whole, there are potential areas for agreement on what responses would better address climate change. Water, sanitation and waste management services are clear areas where some progress has been made but where climate finance could enable a step change in both quality of life and adaptive capacity for those communities living in bairros such as Chamanculo $\mathrm{C}$.

The question is then, how can communities actively participate in partnerships. Most institutional representatives, even those deeply engaged in locally-based programmes for poverty reduction, still spoke of communities as clients to be delivered a project rather than as active agents that could design and deliver (if not whole at least in part) some of those projects. This analysis has to be understood in a changing urban governance context where the prospect of drawing international climate change finance has put climate change at the forefront of the institutional arena and furthermore, has challenged the priorities from developing strategies and plans to demonstrate capacity to deliver action on the ground. Enrolling communities- whether through resilience groups, consultations, NGO actions or community participation, has emerged as a potential avenue through which delivering action on the ground can be demonstrated. But few actors envisaged how communities could play an active role in delivering such action.

What we see here is not a single or a discrete number of potential partnerships but a multitude of encounters that could lead to a temporary consensus and localised forms of action. This is already happening, for example, in the form of a variety of partnerships between local communities and small business that are intervening in waste management. However, while such partnerships encourage optimism, there is a sense of frustration in terms of thinking through a mechanism that will be able to fulfil the great needs of infrastructure in an urban context heavily exposed to climate change risks. Understanding partnerships as a process, and the actors within them as adopting a number of flexible roles that mediate action in a difficult context, provides an optimistic view on the future, but one that has to be balanced with the bleak picture of increasing poverty and lack of services that is pervasive in Maputo.

\section{Conclusions}

This paper tests the value of adopting a cooperative environmental governance paradigm in practical efforts to address the global challenge of climate change, as it materialises in a concrete city like Maputo. First of all, this kind of institutional exercise is often approached, as in this case, as separated from the politics of the city and the country- and yet it is very much dependent on it. In Maputo, active attempts to address poverty reduction and adaptive capacity necessarily overlook the attempts at modernisation, vindication of traditional values or independence that permeate the national political debates.

The construction of partnerships in cooperative environmental governance does not attempt to challenge existing political debates or societal values. Instead, the objective here is to coordinate efforts to make change possible. There is a big step between localised change and a wider transformation that could fully address the equity issues that have traditionally shaped development debates and the new ones that are raised by climate change. Cooperative environmental governance is a call for optimism, a reminder that something can be done and a suggestion to explore the untapped potential of the context. Cooperative environmental governance is, however, not a substitute for action that focuses on highlighting structural inequalities. Should we prioritise other forms of intervention and abandon such cooperative 
governance efforts? Some may argue so. However, it is useful to point out that, if cooperative environmental governance helps to legitimise the role of citizens as generators of knowledge and depositories of action, this constitutes a step towards broader institutional change. From this perspective, however, there is a danger that a cautious optimism about the potential for tapping local forms of knowledge leads to a displacement of responsibilities from government institutions to citizens.

\section{References}

Adger W N, 2006 Fairness in adaptation to climate change (The MIT Press, Cambridge, MA)

Alkire S, Roche J M, Santos M E, Seth S, 2011, "Mozambique Country Briefing. ", in Multidimensional Poverty Index Country Briefing Series. (Poverty \& Human Development Initiative (OPHI) Oxford)

Baletti B, 2014, "Saving the Amazon? Sustainable soy and the new extractivism" Environment and Planning A 46 5-25

Betsill M, Bulkeley $\mathrm{H}, 2007$, "Looking back and thinking ahead: a decade of cities and climate change research" Local Environment 12 447-456

Bourdieu P, 1998 Practical reason: On the theory of action (Stanford University Press, Stanford)

Boyd, E, Ensor, J, Castán Broto, V, Juhola, S, 2014, "Environmentalities of urban climate governance in Maputo, Mozambique" Global Environmental Change 26 140-151.

Boyd E, Folke C, 2011 Adapting institutions: Governance, complexity and social-ecological resilience (Cambridge University Press, Cambridge)

Brinkerhoff J M, 2002, "Government-nonprofit partnership: a defining framework" Public Administration and Development 22 19-30

Castán Broto V, 2012, "Exploring the lay/expert divide: the attribution of responsibilities for coal ash pollution in Tuzla, Bosnia and Herzegovina" Local Environment 17 879-895

Castán Broto V, 2013, "Symbolic Violence and the Politics of Environmental Pollution Science: The Case of Coal Ash Pollution in Bosnia and Herzegovina" Antipode 45 621-640

Castán Broto V, Bulkeley H, 2013, "A survey of urban climate change experiments in 100 cities" Global Environmental Change 23 92-102

Castán Broto V, Oballa B, Junior P, 2013, "Governing climate change for a just city: challenges and lessons from Maputo, Mozambique" Local Environment 18 678-704

Cooke B a U K, 2002, "The Case for Participation as Tyranny", in Participation: the New Tyranny? Ed B a K Cooke, U. (Zed Books, London) pp 1-15

Evans A, Varma S, 2009, "Practicalities of participation in urban IWRM: Perspectives of wastewater management in two cities in Sri Lanka and Bangladesh", in Natural resources forum, Wiley Online Library pp 19-28

Ferreira da Cruz N, Simanques P, Cunha Marques R, 2013, "The hurdles of local governments with PPP contracts in the waste sector" Environment and Planning C: Government and Policy 31 292-307

Forester J, 1999 The Deliberative Practitioner: encouraging participatory planning processes. (MIT Press, Cambridge Mass)

Forsyth T, 2005, "Building deliberative public-private partnerships for waste management in Asia" Geoforum 36 429-439

Forsyth T, 2007, "Promoting the "development dividend" of climate technology transfer: Can crosssector partnerships help?" World Development 35 1684-1698

Glasbergen P, 1998 Co-operative environmental governance: public-private agreements as a policy strategy (Springer Verlag, Amsterdam)

Glasbergen P, Biermann F, Mol A P, 2007 Partnerships, governance and sustainable development: reflections on theory and practice (Edward Elgar Publishing, Amsterdam)

Healey P, 1997 Collaborative planning: shaping places in fragmented societies (Macmillan London) Healey P, 1998, "Building institutional capacity through collaborative approaches to urban planning" Environment and Planning A 30 1531-1546

Holman N, 2013, "Effective strategy implementation: why partnership interconnectivity matters" Environment and Planning C: Government and Policy 31 82-101

INGC, 2011, "Preparing cities- INGC Phase II" (INGC, Maputo)

Innes J E, Booher D E, 2010 Planning with complexity: an introduction to collaborative rationality for public policy (Routledge) 
ISET, 2010, "The Shared Learning Dialogue: Building Stakeholder Capacity and Engagement for Resilience Action", in Climate Resilience in Concept and Practice Working Paper Series (Boulder, Colorado.)

Leck, H, 2013, "The Role of Local Politicians and Political Realities in Shaping Urban Climate Change Agendas: The Case of eThekwini Municipality" Urbanization and Global Environmental Change Viewpoints, No.9.

Leck $\mathrm{H}$, Simon D, 2013, "Fostering multiscalar collaboration and co-operation for effective governance of climate change adaptation" Urban Studies 50 1221-1238

Mason M, 2007, "Collaborative partnerships for urban development: a study of the Vancouver Agreement" Environment and Planning A 39 2366-2382

Meadowcroft J, 1999, "Cooperative management regimes: collaborative problem solving to implement sustainable development" International Negotiation 4 225-254

MMC, UN-Habitat, Agriconsulting, 2012, "Availação detalhada dos impactos resultantes dos eventos das mudanças climáticas no Município de Maputo", (UN-Habitat, Nairobi)

O'Malley L, 2004, "Working in partnership for regeneration - the effect of organisational norms on community groups" Environment and Planning A 36 841-857

Okereke C, Bulkeley $H$, Schroeder H, 2009, "Conceptualizing climate governance beyond the international regime" Global Environmental Politics 9 58-78

Paavola J, Adger W N, 2006, "Fair adaptation to climate change" Ecological Economics 56 594609

Plummer R, Fitzgibbon J, 2004a, "Co-management of natural resources: a proposed framework" Environmental Management 33 876-885

Plummer R, FitzGibbon J, 2004b, "Some observations on the terminology in co-operative environmental management" Journal of Environmental Management 70 63-72

Porter, J. and Demeritt, D. (2012) "Flood-risk management, mapping, and planning: the institutional politics of decision support in England" Environment and Planning A 44 2359-2378.

Potter J, Wetherell M, 1987 Discourse and social psychology: Beyond attitudes and behaviour (Sage, London)

Reed M S, Graves A, Dandy N, Posthumus H, Hubacek K, Morris J, Prell C, Quinn C H, Stringer L C, 2009, "Who's in and why? A typology of stakeholder analysis methods for natural resource management" Journal of Environmental Management 90 1933-1949

Satterthwaite D, 2007 Adapting to climate change in urban areas: the possibilities and constraints in low-and middle-income nations (lied)

Schroeder H, Burch S, Rayner S, 2013, "Novel multisector networks and entrepreneurship in urban climate governance" Environment and Planning C: Government and Policy 31 761-768

Selsky J W, Parker B, 2005, "Cross-Sector Partnerships to Address Social Issues: Challenges to Theory and Practice" Journal of Management 31 849-873

Sengupta U, 2013, "Inclusive development? A state-led land development model in New Town, Kolkata" Environment and Planning C: Government and Policy 31 357-376

Sherlock K L, Kirk E A, Reeves A D, 2004, "Just the usual suspects? Partnerships and environmental regulation" Environment and Planning C: Government and Policy 22 651-666

Siemiatycki M, 2011, "Urban transportation public - private partnerships: drivers of uneven development?" Environment and Planning A 43 1707-1722

UN-Habitat, 2009, "Planning sustainable cities: Global Report on Human Settlements. 2009" Earthscan, London

Watson V, 2009, "'The planned city sweeps the poor away...': Urban planning and 21st century urbanisation" Progress in Planning 72 151-193

Wetherell M, 1998, "Positioning and Interpretative Repertoires: Conversation Analysis and PostStructuralism in Dialogue" Discourse \& Society $9387-412$ 